\title{
Pengaruh Pendidikan Dan Pelatihan Terhadap Produktivitas Kerja Karyawan Bagian Produksi Pada Cv. Danagung D'briquettes
}

\author{
Tri Isnawati, Jajuk Herawati, Ignatius Soni Kurniawan \\ Universitas Sarjanawiyata Tamansiswa \\ Email:Triisna66@gmail.com, Jajuk.herawati@ustjogja.ac.id, Soni_kurniawan@ustjogja.ac.id \\ Diterima:April 2020; Dipublikasikan: Juli 2020
}

\begin{abstract}
ABSTRAK
Penelitian ini bertujuan untuk menguji pengaruh pendidikan dan pelatihan terhadap produktivitas kerja karyawan CV. Danagung D'Briquettes. Populasi dalam penelitian ini adalah seluruh karyawan bagian produksi yang berjumlah 46 orang sebagai populasi. Metode penelitian ini menggunakan non probability sampling dengan metode sampling jenuh. Teknik pengumpulan data menggunakan angket, sedangkan teknik analisis data menggunakan validitas, reliabilitas, statistik deskriptif, uji asumsi klasik, uji linier berganda dan koefisien determinasi. Hasil penelitian menunjukkan bahwa (1) Pendidikan berpengaruh positif terhadap produktivitas karyawan, (2) Pelatihan berpengaruh positif terhadap produktivitas karyawan, (3) Pendidikan dan pelatihan secara simultan berpengaruh positif dan signifikan terhadap produktivitas karyawan.
\end{abstract}

Kata Kunci: pendidikan, pelatihan dan produktivitas karyawan

\begin{abstract}
ABSTACT
This research aims to test the effect of education and training on employee productivity of CV. Danagung D'Briquettes. The population in this study used all production section employees totaling 46 people as the population. This research method uses non probability sampling with saturated sampling method. Data collection techniques used questionnaires, while data analysis techniques used validity, reliability, descriptive statistics, classic assumption tests, multiple linear tests and coefficient of determination. The results showed that (1) Education had a positive effect on employee productivity, (2) Training had a positive effect on employee productivity, (3) Education and training simultaneously had a positive and significant effect on employee productivity..
\end{abstract}

Keywords: education, training and employee productivity

\section{PENDAHULUAN}

Manusia menjadi faktor utama dalam setiap kegiatan operasional dalam suatu perusahaan ,maka pengelolaan sumber daya manusia harus semaksimal mungkin. Perusahaan harus mampu memberikan perhatian serta perlakuan khusus terhadap sumber daya manusia terutama tenaga kerja dalam bidang produksi. CV. Danagung D'Briquettes merupakan perusahaan yang bergerak dibidang pengolahan dan turunannya, yaitu perusahaan yang memproduksi briket dengan bahan baku utama dari arang tempurung kelapa. Briket tempurung kelapa ini lebih banyak diekspor keluar negeri dibandingkan dipasarkan dalam negeri. Pada CV. Danagung D'Briquettes baru-baru ini menambah peralatan maupun mesin produksi yang lebih canggih. Adanya pergantian mesin baru membuat karyawan harus mampu beradaptasi lagi dalam menjalankan tugas dan tanggungjawabnya. Kondisi seperti ini membuat kemampuan karyawan dalam pengoperasian mesin menjadi sebuah kendala dalam proses produksi. Karyawan mengalami kesulitan ketika mengoperasikan mesin baru dikarenakan para karyawan masih terbiasa dengan cara pengoperasian mesin lama. Kendala pengoperasian mesin baru ini berakibat pada turunnya produktivitas kerja, maka perusahaan harus memperhatiakan sumber daya manusia yang menggerakan proses produksi, karena proses produksi hanya dapat menghasilkan kuantitas dan kualitas produk yang diharapkan jika tenaga kerjanya memiliki kualitas fisik, pengetahuan, keterampilan, kompetensi yang diperlukan untuk mengubah masukan menjadi keluaran produksi (Wiranto, 2015).

Kualitas sumber daya manusia dapat terpenuhi dengan memberikan arahan dan pelatihan pendidikan tenaga kerja (Nora Anisa, 2014). Dengan adanya pendidikan dan pelatihan dapat menambah pengetahuan dan meningkatkan produktivitas kerja karyawan (Sumarsono, 2009). Memperhatikan berapa pentingnya peranan manusia dalam satu perusahaan, maka suatu perusahaan dapat dikatakan berkembang dan tidaknya tergantung pada baik buruknya kualitas tenaga kerja. Semakin baik sumber daya manusia yang dimiliki maka semakin baik pula hasil yang 
akan dicapai, demikian pula sebaiknya semakin rendah sumber daya manusia maka semakin rendah pula hasil yang dicapai (I Gede Novran, 2015). Karena keberhasilan suatu perusahaan ditentukan oleh sumber daya manusia yang berkualitas, dengan adanya sumber daya manusia yang berkualitas maka dapat mengendalikan perusahaan tersebut.

\section{TINJAUAN PUSTAKA DAN PENGEMBANGAN HIPOTESIS}

Tujuan pendidikan untuk meningkatkan pengetahuan, pengertian dan sikap para tenaga kerja sehingga mereka dapat lebih menyesuaikan dengan lingkungan kerja. Pendididikan berhubungan dengan menambah pengetahuan umum dan pengertian tentang seluruh lingkungan kerja (Sastrohadiwiryo, 2003). Konsep sistem pendidikan dan pelatihan (diklat) adalah upaya untuk meningkatkan, mengembangkan dan membentuk pegawai melalui pelatihan berjenjang, pelatihan kursus, pelatihan fungsional, dan pelatihan operasional yang banyak diterapkan oleh suatu organisasi dalam rangka meningkatkan kemampuan kerja karyawan (Pujirahayu, 2008). Pelatihan merupakan proses mengajarkan karyawan baru atau karyawan lama melalui ketrampilan dasar yang mereka butuhkan dalam menjalankan pekerjaan mereka (Susanto, 2013). Produktivitas dapat diukur dari segi efektivitas dan efisiensi yang difokuskan pada aspek seperti kualitas dan kuantitas, banyaknya waktu yang digunakan untuk mencapai hasil akhir dan penggunaan sumber daya secara optimal (Yuniarsih dkk, 2008). Produktivitas ditentukan oleh dukungan semua sumber daya organisasi yang dapat diukur dari segi efektivitas dan efisiensi, yang difokuskan pada aspek-aspek yaitu : kualitas dan kuantitasnya, lamanya waktu yang digunakan untuk mencapai hasil akhir dan penggunaan sumber daya secara optimal.

Pendidikan membantu mengembangkan kemampuan berfikir para karyawan dan meningkatkan seseorang unutk menerima tanggungjawab dan tugas tugasnya sehingga berpengaruh dengan meningkatnya produktivitas kerja. Penelitian Hanna Riani (2016) dan Bambang Hermawanto (2014) yang juga menyatakan bahwa pendidikan berpengaruh positif terhadap produktivitas kerja.

H1 : Pendidikan berpengaruh postitif terhadap produktivitas kerja.

Adanya pelatihan akan membantu meningkatkan produktivitas yang lebih baik, sehingga mampu meningkatkan kualitas kerja dan ketrampilan karyawan baru maupun lama. Penelitian Nora Anisa (2014), Hendra Susilo (2016) dan Luh Putu dkk, (2016) yang juga menyatakan bahwa pelatihan berpengaruh terhadap produktivitas kerja.

$\mathrm{H} 2$ : Pelatihan berpengaruh positif terhadap produktivitas kerja.

Hubungan adanya pendidikan dan pelatihan dengan produktivitas saling berhubungan karena dapat mencapai hasil akhir yang baik dengan kualitas dan kuantitas yang optimal. Penelitian Chainar Elli (2017) dan Bambang Hermanto (2014) yang menyatakan bahwa pendidikan dan pelatihan secara simultan berpengaruh signifikan terhadap produktivitas kerja.

H3 : Pendidikan dan pelatihan secara simultan berpengaruh signifikan terhadap produktivitas kerja.

\section{METODE PENELITIAN}

Penelitian yang akan dilakukan bersifat deskriptif dengan pendekatan kuantitatif, yaitu merupakan metode penelitian yang disajikan dengan angka-angka. Penelitian ini menguji dua variabel yaitu variabel independen dan variabel dependen. Variabel independen dalam penelitian ini adalah pendidikan dan pelatihan, sednagkan variabel dependen dalam penelitian ini adalah produktivitas kerja.Penelitian menggunakan seluruh karyawan bagian produksi CV. Danagung D'Briquettes sebagai populasi. Metode pengambilan data menggunakan kuisioner yang diambil dengan teknik pengambilan sampel non probability dengan metode sampel jenuh yaitu seluruh karyawan bagian produksi yang berjumlah 46 karyawan. Sumber data dari penelitian ini yaitu data primer dan data sekunder. Data primer dari penelitian dikumpulkan sendiri oleh peneliti dengan penyebaran kuisioner karyawan bagian produksi CV. Danagung D'Briquettes. Pendidikan menggunakan indikator dari Edi Sutrisno (2003). Pelatihan menggunakan indikator dari Veithzal Rivai (2006:226) dalam (Jeniffer,2016). Produktivitas kerja menggunakan indikator dari Sendramayati (2001:57) dalam (Jeniffer,2016). 
Uji Kualitas Data

HASIL DAN PEMBAHASAN

Tabel 1. Uji Validitas dan Reliabilitas

\begin{tabular}{llllll}
\hline \multicolumn{2}{c}{$\begin{array}{c}\text { Pendidikan } \\
\text { (PDD) }\end{array}$} & & $\begin{array}{l}\text { Pelatihan } \\
\text { (PLH) }\end{array}$ & $\begin{array}{c}\text { Produktivitas } \\
\text { Kerja } \\
\text { (PK) }\end{array}$ \\
\hline PDD1 & 0,921 & PLH1 & 0,463 & PK1 & 0,884 \\
PDD2 & 0,835 & PLH2 & 0,825 & PK2 & 0,896 \\
PDD3 & 0,928 & PLH3 & 0,882 & PK3 & 0,824 \\
PDD4 & 0,914 & PLH4 & 0,910 & PK4 & 0,956 \\
& & & & PK5 & 0,872 \\
\hline $\begin{array}{l}\text { Cronbach's } \\
\text { alpha }\end{array}$ & $\mathbf{0 , 9 2 0}$ & & $\mathbf{0 , 7 6 1}$ & & $\mathbf{0 , 9 3 0}$ \\
\hline
\end{tabular}

Indikator valid pada (Tabel.1) ditunjukan nilai $r$-hitung > r-table 0,297 (two tail $\alpha$ 5\%) semua item pada indikator pendidikan, pelatihan dan produktivitas kerja adalah valid. Hasil cronbach's alpha besed on standarized item variabel pendidikan $(0,920)$, pelatihan $(0,761)$ dan produktivitas kerja $(0,930)$.

\begin{tabular}{|c|c|c|}
\hline \multicolumn{2}{|c|}{ Karkteristik Responden } & \multirow{2}{*}{$\frac{\%}{65,9}$} \\
\hline Jenis Kelamin & Laki-laki & \\
\hline & Perempuan & 34,1 \\
\hline \multirow[t]{3}{*}{ Usia } & $<20$ tahun & 34,1 \\
\hline & 21-30 tahun & 59,1 \\
\hline & 31-40 tahun & 6,8 \\
\hline \multirow[t]{2}{*}{ Pendidikan } & SMP & 38,6 \\
\hline & SMA & 61,4 \\
\hline \multirow[t]{3}{*}{ Lama bekerja } & $<2$ tahun & 34,1 \\
\hline & 3-5 tahun & 55,8 \\
\hline & 6-8 tahun & 9,1 \\
\hline \multirow[t]{2}{*}{ Status } & Lajang & 31,8 \\
\hline & Menikah & 68,2 \\
\hline
\end{tabular}

Karakteristik responden (Tabel 2) menunjukan bahwa karyawan laki-laki dalam perusahaan sebesar $65,9 \%$ lebih banyak dibandingkan karyawan perempuan yang hanya sebesar $34,1 \%$. Sebagian besar pegawai karyawan berusia 21-30 tahun $(59,1 \%)$, karyawan berusia $<20$ tahun $(34,1 \%)$ dan bahkan ada juga karyawan berusia diatas 30 tahun $(6,8 \%)$. Pendidikan terakhir karyawan didominasi lulusan SMA sebesar 61,4\% dan lululsan SMP sebesar 38,6\%. Presentase karyawan yang telah bekerja $<2$ tahun sebesar $(34,1 \%)$, karyawan yang bekerja 3-5 tahun sebesar $(55,8)$, sedangkan karyawan yang sudah bekerja 6-8 tahun hanya sekitar 9,1\%. Status karyawan didominasi sudah menikah sebesar $68,2 \%$, sedangkan yang lajang sebesar $31,8 \%$.

Hasil dari Uji Normalitas (Tabel 3) dapat diketahui bahwa nilai Kolmogrow Smirnov Z $0,910>0,05$ dan nilai Asyamp Sig. (-2 tailed) 0,379>0,05 maka dapat dikatakan berdistribusi normal. Hasil Uji Multikolinieritas menunjukkan bahwa semua variabel independen terhadap variabel dependen nilai VIF $<10$ dan Tolerance $>0,1$, maka dapat disimpulkan bahwa tidak terjadi multikolinieritas. Hasil Uji Heteroskedastisitas menggunakan Uji Glejser menunjukan semua variabel independe nilai sig > 0,05 yang artinya tidak terjadi heteroskedastisitas. 
Tabel 3. Uji Asumsi Klasik

\begin{tabular}{|c|c|c|c|c|c|c|c|c|}
\hline \multirow[b]{2}{*}{$\begin{array}{l}\text { Variabel } \\
\text { Independen }\end{array}$} & \multirow[b]{2}{*}{$\begin{array}{l}\text { Variabel } \\
\text { Dependen }\end{array}$} & \multicolumn{3}{|c|}{$\begin{array}{c}\text { Uji } \\
\text { Normalitas }\end{array}$} & \multicolumn{2}{|c|}{$\begin{array}{c}\text { Uji } \\
\text { Multikolinieritas }\end{array}$} & \multirow{2}{*}{\multicolumn{2}{|c|}{$\begin{array}{c}\text { Uji } \\
\text { Heteroskedastisita } \\
\text { s } \\
\text { Sig }\end{array}$}} \\
\hline & & $\begin{array}{l}\text { Kolmogr } \\
\text { ov } \\
\text { Smirnov } \\
Z\end{array}$ & \multirow{2}{*}{\multicolumn{2}{|c|}{$\begin{array}{c}\text { Asyimp } \\
\text { sig } \\
(2 \text { tailed } \\
\quad)\end{array}$}} & VIF & $\begin{array}{c}\text { Toleranc } \\
\text { e }\end{array}$ & & \\
\hline PDD & & & & & 1,183 & 0,845 & \multicolumn{2}{|c|}{0,263} \\
\hline PLH & PK & 0,910 & \multicolumn{2}{|c|}{0,379} & 1,183 & 0,845 & \multicolumn{2}{|c|}{0,672} \\
\hline \multicolumn{9}{|c|}{ Tabel 4. Uji Analisis Berganda } \\
\hline \multicolumn{2}{|c|}{ Model } & \multicolumn{2}{|c|}{$\begin{array}{c}\text { Untandarized } \\
\text { B }\end{array}$} & \multicolumn{2}{|c|}{$\begin{array}{l}\text { Coefficients } \\
\text { Std. Error }\end{array}$} & $\begin{array}{c}\text { Standarized } \\
\text { Coefficients } \\
\text { Beta }\end{array}$ & $\mathbf{T}$ & Sig \\
\hline \multicolumn{2}{|c|}{ (Constant) } & 3,92 & & \multicolumn{2}{|c|}{2,757} & & 1,423 & 0,162 \\
\hline \multicolumn{2}{|c|}{ PDD } & 0,531 & & \multicolumn{2}{|c|}{0,151} & 0,436 & 3,519 & 0,001 \\
\hline \multicolumn{2}{|c|}{ PLH } & $0,49^{7}$ & & \multicolumn{2}{|c|}{0,161} & 0,382 & 3,079 & 0,004 \\
\hline
\end{tabular}

Hasil pengujian persamaan regresi pada table diatas dapat dijelaskan sebagai berikut.

$\mathrm{PK}=3.924+0.530 \mathrm{PDD}+0.497 \mathrm{PLH}$

Berdasarkan hasil pengujian dan persamaan regresi Tabel 4. diatas terdapat angka konstanta 3,924. Kemudian nilai 0,530 PDD berarti setiap penambahan atau pengurangan 1 (satu) skor pendidikan akan mempengaruhi produktivitas kerja sebanyak 0,530 point, dan nilai 0,497 PLT berarti setiap penambahan atau pengurangan 1 (satu) skor pelatihan mempengaruhi produktivitas kerja sebesar 0,497.

Tabel 5 Uji Hipotesis

\begin{tabular}{|c|c|c|c|c|c|c|c|c|}
\hline \multirow[b]{2}{*}{$\begin{array}{c}\text { Variabel } \\
\text { Independen }\end{array}$} & \multirow[b]{2}{*}{$\begin{array}{l}\text { Variabel } \\
\text { Dependen }\end{array}$} & \multicolumn{2}{|c|}{ Uji t } & \multicolumn{2}{|c|}{ Uji F } & \multicolumn{2}{|c|}{$\begin{array}{c}\text { Koefisien } \\
\text { Determinasi }\end{array}$} & \multirow{2}{*}{$\begin{array}{c}\text { Stan } \\
\text { dariz } \\
\text { ed } \\
\text { Beta } \\
\text { Coefi } \\
\text { cient }\end{array}$} \\
\hline & & t-hitung & Sig & $\mathbf{F}$ & Sig & $\begin{array}{c}\mathbf{R} \\
\text { Square }\end{array}$ & $\begin{array}{l}\text { Adjusted } \\
R \text { Square }\end{array}$ & \\
\hline PDD & & 3,519 & 0,001 & & & & & 0,436 \\
\hline PLH & $1 \pi$ & 3,079 & 0,004 & 17,703 & 0,000 & 0,401 & $0,+41$ & 0,382 \\
\hline
\end{tabular}

Berdasarkan uji t (parsial) pada (Tabel 5) pendidikan menunjukan bahwa nilai sig 0,001/2 $<0,05$ maka dapat disimpulkan pendidikan berpengaruh positif terhadap produktivitas kerja dan pelatihan menunjukan bahwa nilai sig 0,004/2 $<0,05$ maka pelatihan berpengaruh positif terhadap produktivitas kerja. Uji $\mathrm{F}$ menunjukan nilai sig $0,000<0,05$ maka pendidikan dan pelatihan berpengaruh simultan terhadap produktivitas kerja. Uji Koefesien Determinasi menunjukan Adjusted $R$ Square sebesar 0,441 yang artinya bahwa besarnya kontribusi pendidikan dan pelatihan terhadap produktivitas kerja sebesar $44,1 \%$, sedangkan $55,9 \%$ dipengaruhi oleh faktor lain yang tidak diteliti dalam penelitian ini. Hasil Standarized Beta Coeficient variabel yang paling berpengaruh dalam penelitian ini adalah pendidikan, diikuti variabel pelatiahan. 


\section{Pembahasan}

Hasil penelitian menunjukan bahwa pendidikan berpengaruh positif terhadap kproduktivitas kerja karyawan bagian produksi CV. Danagung D'briquette. Hal ini sejalan dengan penelitian Hanna Rianita Putri (2016) yang menyatakan bahwa pendidikan berpengaruh positif terhadap produktivitas kerja. Hasil penelitian ini juga menunjukan bahwa pelatihan berpengaruh positif terhadap produktivitas kerja pada karyawan bagian. Hal ini sejalan dengan penelitian Nora Anisa (2014) yang menyatakan bahwa pelatihan berpengaruh positif terhadap produktivitas kerja. Chainar Elli (2017) juga menyatakan pelatihan berpengaruh positif terhadap produktivitas kerja, pelatihan yang diterapkan oleh perusahaan dapat meningkatkan kemampuan kerja karyawan. Berdasarkan hasil uji $\mathrm{F}$ penelitian ini menunjukkan bahwa pendidikan dan pelatihan secara simultan atau bersama-sama berpengaruh positif dan signifikan terhadap produktivitas kerja karyawan bagian produksi.Variabel independen memiliki sumbangan efektif total koefisien determinasi $\left(\mathrm{R}^{2}\right)$ terhadap variabel dependen sebesar $44,1 \%$, sedangkan sisanya dipengaruhi oleh faktor lain yang tidak diteliti dalam penelitian ini. Pada hasil Standardized Coefficient Beta variabel yang paling dominan dalam penelitian ini adalah pendidikan kemudian diikuti variabel pelatihan.

\section{Kesimpulan}

\section{KESIMPULAN DAN SARAN}

Berdasarkan hasil penelitian yang dilakukan pada CV. Danagung D'briquette mengenai pengaruh pendidikan dan pelatihan terhadap produktivitas kerjayawan bagian produksi maka dapat ditarik kesimpulan yaitu Pendidikan berpengaruh positif terhadap produktivitas kerja, jika pendidikan semakin baik maka dapat meningkatkan pengetahuan dan sikap tenaga kerja sehingga mereka mampu menyesuaikan diri dengan lingkungan kerja. Pelatihan berpengaruh positif terhadap produktivitas kerja, pelaksanaan pelatihan CV. Danagung D'briquette sudah terlaksana dengan baik sesuai konsep yang telah disepakati sehingga karyawan yang mengikuti pelatihan dapat menangkap dan memahami materi yang diberikan, sehingga skill dan knowledge para karyawan mengalami peningkatan. Pendidikan dan pelatihan secara simultan berpengaruh positif dan signifikan terhadap produktivitas kerja karyawan.

\section{Saran}

Disarankan kepada pimpinan perusahaan untuk tetap mengadakan pelatihan yang berkualitas agar produktivitas kerja karyawan dalam melaksanakan pekerjaan hasilnya akan lebih memuaskan, seperti jadwal pelatihan terjadwal dan dengan metode pelatihan yang sesuai dengan kebutuhan karyawan. Hal ini bertujuan agar karyawan lebih mampu dalam melaksanakan tugas dan tanggung jawab yang diberikan kepadanya. Bagi peneliti yang akan datang dapat mengembangkan penelitian mengenai produktivitas kerja dengan menambah atau mengganti variabel lain yang dapat lebih mempengaruhi terhadap produktivitas kerja, seperti insentif maupun variabel lainnya.

\section{DAFTAR PUSTAKA}

Patras, Y. E., Hidayat, R., Lian, B., Fitria, H., \& Apriana, D. (2019). (Jurnal Manajemen, Kepemimpinan, dan Supervisi Pendidikan) P-ISSN: 2548-7094 E-ISSN 2614-8021. 4(1).

Hastuti, T. (2008). Pengaruh Training terhadap Produktivitas Kerja Karyawan Bagian Produksi pada PT . Nestle Indonesia Kejayan Factory Pasuruan. Jurnal Manajemen, Akuntansi Dan Bisnis.

De Grip, A., \& Sauermann, J. (2013). The effect of training on productivity: The transfer of on-thejob training from the perspective of economics. Educational Research Review, 8, 28-36. https://doi.org/10.1016/j.edurev.2012.05.005

Putri, H. R. (2016). Pengaruh pendidikan, pengalaman kerja, dan jenis kelamin terhadap produktivitas kerja karyawan bagian produksi CV. Karunia Abadi Wonosobo. Jurnal Pendidikan Dan Ekonomi, 5(4), 292-300.

Manajemen, J., Ekonomi, F., Ilmu, D. A. N., Negeri, U. I., Syarif, S., \& Riau, K. (2012). Pengaruh Program Pendidikan Dan Karyawan Bagian Produksi Pada Pt. Multi.

Ria, C. E. (2017). Pengaruh Pendidikan dan Latihan Tenaga Kerja Terhadap Peningkatan Produktifitas Kerja Karyawan Pada Sumber PT . Sumber Rezeki Medan. 6(1), 80-100. 
Baitul, D. I., Wat, M., \& Bmt, T. (2013). Pengaruh Pelatihan Dan Motivasi Kerja Terhadap Produktivitas Kerja Karyawan. 3(09), 112-124.

Putu, L., Apriliyantini, E., Bagia, I. W., \& Suwendra, I. W. (2016). Pengaruh Pelatihan Dan Kepuasan Kerja Terhadap Produktivitas Kerja Karyawan Bagian Produksi. Manajemen, 4(1), 1-7.

Terhadap, O., Pegawai, K., Keuangan, K., Iv, K., Yang, D., \& Di, B. (2016). Journal of Management Vol.2 No.2, Maret 2016. 2(2).

Ghozali,I.(2013). Analisis Aplikasi Multivariate Dengan Program IBM SPSS 19. (Badan Penerbit Universitas Diponegoro,Ed) (5th ed). Semarang

Anisa, N., \& Sinulingga, B. (2014). Pengaruh Pendidikan Dan Latihan Tenaga Kerja Terhadap Peningkatan Produktivitas Kerja Pegawaipt. Shamrock Corpora. Jurnal Mantik Penusa, 15(1), 1-7.

SUSILO PRADANA, H. (2016). Pengaruh Pelatihan Dan Motivasi Kerja Terhadap Produktivitas Kerja Karyawan Bagian Produksi Di Pg.Tjoekir, Jombang. Jurnal Ilmu Manajemen (JIM), 4(1), 362-371. 